\title{
Behavioral Biases in Forward Rates as Forecasts of Future Exchange Rates: Evidence of Systematic Pessimism and Under-Reaction
}

\author{
Raj Aggarwal \\ University of Akron, U.S.A. \\ Sijing Zong \\ California State University-Stanislaus, U.S.A.
}

\begin{abstract}
Even though the forward-spot relationship in currency markets is very important for policy makers and for corporate and investment managers, it remains a theoretical and empirical puzzle. In theory the forward rate should be an unbiased forecast of the future spot rate, but this hypothesis has little empirical support. For the currencies of the nine major industrialized countries, this paper documents that in spite of the very high trading volumes in currency markets, consistent with evidence for other asset markets, revisions in the forward rate forecasts of the future spot exchange rate reflect systematic pessimism and under-reaction to new information (JEL: F31, G14, F47, G15).
\end{abstract}

Keywords: exchange rates, forward bias, market rationality, under-reaction

\section{Introduction}

The relation between forward and spot rates in foreign exchange markets remains very interesting, not only to policy makers but also to corporate and investment managers. Many investment, hedging, and macroeconomic decisions are influenced and determined by the nature of this relationship (the effectiveness of the forward rate as a forecast of the future spot rate). However, the currency market forward-spot

* The authors would like to thank two anonymous reviewers, colleagues, A Dania, participants in the Finance Research Seminar Series at Kent State University, 2005 Eastern Finance Association, and 2004 Financial Management Association meetings for useful comments, and Dr. Richard Levich of New York University for providing the exchange rate data used in this paper. However, the authors remain solely responsible for the contents.

(Multinational Finance Journal, 2008, vol. 12, no. 3/4, pp. 241-277)

Quarterly publication of the Multinational Finance Society, a nonprofit corporation.

(C) Global Business Publications. All rights reserved.

DOI: $10.17578 / 12-3 / 4-5$ 
relation remains an empirical and theoretical puzzle.

According to the theoretically elegant and widely assumed "Rational Expectations" paradigm, markets use all available information efficiently in forming expectations and such expectations are rational and unbiased so that forecast errors are uncorrelated and have zero mean. Among the empirical results that seem to contradict this theoretically elegant hypothesis, is evidence from the most liquid of all markets, the foreign exchange markets, where forward rates (and survey forecasts) have been documented to be consistently biased forecasts of future spot rates, as changes in the future spot rates are generally negatively related to the forward discount. Forward rate forecasts of future spot rates clearly violate the rational expectations hypothesis (Chernenko et al. [2004]). So far, risk premia or other foreign exchange models are unable to explain this bias and non-rationality (e.g., the survey by Engel [1996]).

The wide range of models of risk premia in the foreign exchange market that have been tested unsuccessfully include the capital asset pricing model, models of changing second moments (Hansen and Hodrick [1983], Cumby [1988]), consumption based asset pricing models including models to account for non-additive preferences (Backus et al. [1993], Bansal et al. [1995]), deviations from expected utility (Bekaert et al. [1997]), and trade frictions (Hollifield and Uppal [1997]). While other literature on this topic has explored the role of peso problems, learning, and irrational expectations (Lewis [1995], Frankel and Rose [1994]). Even though this research is occasionally promising, it has also not resulted in any significant changes in the overall conclusions of significant non-rationality in forward currency markets noted above (Aggarwal [2004]).

A recent body of research on equity markets has documented systematic over-reaction at long horizons and under-reaction at short horizons (Jackson and Johnson [2006], Poteshman [2001], Daniel et al. [1998]). Others have noted systematic pessimism or optimism in market responses to new information (Ball and Croushore [2001]). These systematic behavioral patterns are also supported by studies of the forecast revisions of financial analysts responding to updated accounting information (Karamanou and Raedy [2000]) and of economic forecasters with macroeconomic data (Ghosh [1997]). Such deviations from rationality and efficiency also seem to reflect well-documented behavioral patterns among investors (Barberis et al. [1998], Hirshleifer [2001]). These systematic non-rational behavioral patterns may persist due to limited arbitrage (e.g., Shleifer and Vishny 
[1997]). Even though trading volumes in currency markets are much higher, systematic deviations from rationality have also been documented in these markets (Lewis, [1989]). Are foreign exchange markets characterized by the behavioral biases seen in equity markets?

This paper examines the ability of currency forward rates to forecast future spot rate changes and to revise such forecasts with the availability of updated information. In particular, this paper examines if revisions in the forward rate forecasts of future spot currency rates reflect systematic over- or under-reaction and if they are systematically pessimistic or optimistic? We find that the nine major currencies examined share similar patterns in the forecast revision processes and we document significant systematic under-reaction to new information and consistent pessimism in forecast revisions.

Next we review the literature on biases in forward rates, on investor belief revisions, and on the common methodologies for testing forward rates as unbiased predictors of future spot rates. Following that we describe the data and methodology used in this paper, present the empirical results, and the final section concludes.

\section{Rationality and Efficiency in Asset Markets}

Previous tests of rationality of forward expectations mostly focus on the one-period ahead forecasts. In this paper we note that investors and markets continually revise their expectations with new information. However, as the burgeoning literature on over- and under-reaction in equity markets notes, such revisions may be influenced by behavioral patterns that allow prices to deviate from market rationality and efficiency (Abel [2002], Barberis et al. [1998]). As this literature notes, costly and asymmetric information and limitations in arbitrage can lead to systematic deviations from rational expectations and to biased forecasts. Fortunately, recent literature on asset price behavior has started to explain how the intersection of psychology and decision science can illuminate systematic behavioral patterns observed in asset markets.

\section{A. Theoretical Bases for Behavioral Biases}

Market participants generally have limited ability to assess and process information and reflect many behavioral biases including overconfidence (e.g., Daniel and Titman, [1999]). Overconfidence among market participants has two effects, i.e., investor's overweight 
prior beliefs and underweight new information (Barberis et al. [1998]). Recent work by Cecchetti et al. (2000) develops a model that explains why investors may be systematically pessimistic as they violate rational expectations by being unusually risk averse. Barberis et al. (1998) develop a theoretical model that explains short horizon under-reaction and long horizon over-reaction based on investors being subject to conservatism and representativeness - two well-known cognitive biases. With conservatism, an investor sticks to prior beliefs more strongly that is warranted while with representativeness investors finds patterns in data too readily. The interaction of these two behavioral biases makes investors under-react to information that is preceded by an inadequate quantity of similar information and investors over-react to information preceded by large amounts of similar information.

\section{B. Empirical Evidence of Behavioral Biases in Asset Markets}

The empirical literature documents these theoretical predictions of systematic deviations from rational expectations. Aggarwal, Mohanty, and Song (1995) document systematic deviations from rationality for professional forecasts of a number of major macroeconomic series. Similar results are found for revisions among economic forecasters (Ghosh [1997]). Ashiya and Doi (2001) show extensive herding among Japanese institutional forecasters. Others have noted systematic pessimism in market responses to new information in forecasts of inflation (Ball and Croushore [2001]). Karamanou and Raedy (2000), and Amir and Ganzach (1998) show that security analysts under- react to new information and Jackson and Johnson (2006) show a generalized pattern of under-reaction in equity markets.

A recent body of equity markets literature has started to explore systematically the reasons for such deviations from rationality and efficiency. This literature has noted that financial markets are not frictionless (e.g., transactions and information costs) and face limits on the nature and extent of arbitrage (e.g., Schleifer and Vishny [1997]). For example, arbitrage requires capital and is usually risky. Because of the skill and connections required, arbitrage may be limited by agency problems between specialized skilled arbitrageurs and other investors. In addition to limited arbitrage, market prices may deviate from rational efficient levels due to positive feedback trading as informed investors try to take advantage of the uninformed (De Long et al. [1990]). Indeed, investors and mutual fund managers have been shown to engage in herding behavior (e.g., Wermers [1999], Nofsinger and Sias [1999]). 
In addition to institutional factors, there are systematic behavioral biases that contribute to deviations from rational efficient markets. These systematic deviations from rationality and efficiency seem to reflect well-documented behavioral patterns among investors and other economic agents (Barberis et al. [1998], Hirshleifer [2001]). Shiller (2002) assesses and summarizes much of this literature on the behavioral biases in investor decisions.

Several recent papers (Lakonishok et al. [1994], La Porta [1996]) that study stock market price behavior contend that investors irrationally extrapolate recent prices and thus make wrong forecasts. For example, investors observe abnormal price movement and erroneously project that the trend is to continue. Abel (2002) shows that systematic pessimism and doubt are consistent with observed equity market behavior. There is evidence among investors that they are prone to pessimism and over-reaction at long horizons and under-reaction at short horizons (Poteshman [2001], Daniel et al. [1998]). These systematic deviations from rationality and efficiency seem to reflect well-documented behavioral patterns among investors and other economic agents (Barberis et al. [1998], Hirshleifer [2001]).

\section{Evidence of Behavioral Biases in Currency Markets}

Even though trading volumes in currency markets are much higher than in equity markets, deviations from rationality have been documented in these markets as well (DeGrauwe et al. [2005]; Frankel and Froot [1986]; Levich [1979]; Ashiya [2002]; Villanueva [2005]). Lewis (1989) suggests that such deviations from rationality may be due to a combination of Bayesian learning and risk premia. More specifically, Bekaert and Hodrick (2001) summarize three potential reasons for the rejection of forward rate as an unbiased future spot rate. The first is that the expectation hypothesis $(E H)$ is based on the assumption of rational expectations and unlimited arbitrage. The second is the presence of time-varying risk premiums. The third is that the tests themselves may lead to false rejections because of poor properties in finite samples. So, forward rates may not be rational forecasts of future spot rates and it may be difficult to assess sources of such bias.

Nevertheless, like other asset markets, currency markets may also be subject to speculative excesses. Frankel and Froot (1990) contend that the mid 1980s over-valuation of the U.S. dollar is an example of a speculative bubble. DeGrauwe et al. (2005) suggest that bias in forward exchange rates may result from behavioral bubbles that arise when 
investors use trading rules that have been profitable in prior periods. Another factor contributing to deviations from rationality in currency markets is intervention by central banks, a powerful well informed group of market participants whose goals may deviate greatly from economic profit maximization (e.g., Bonser-Neal [1996], Humpage [1987]). Bacchetta and Wincoop (2005) develop a model based on costly information and rational inattention in another theoretical attempt to explain forward exchange rate biases. However, in spite of these recent models that try to explain forward exchange rate biases, there is little empirical literature on behavioral biases in currency markets and there does not seem to be any empirical literature on optimism and pessimism in foreign exchange forward markets.

As this brief literature review indicates, it has been widely documented that forward rates reflect systematic biases as forecasts of future spot rates. However, the sources of this bias are still unclear. In this paper we not only test the rationality of the forward rate as a forecast of the future spot rate, but we also examine how new information is incorporated in changes in the forward rate as the forecast period shortens and new information becomes available. We test if the resulting revisions in the forward rate forecast of the future spot rate are characterized by systematic behavioral biases of under/over reaction and optimism and pessimism.

Specifically, in this paper, we investigate the nature of the revision process reflected in how the forward exchange rate changes as a forecast of a future spot rate (as reflected in the differences between six month and three month forward rates as forecasts of the same future spot rate). We examine if the biases and deviations from rationality and efficiency noted in studies of other asset markets also hold for the much more liquid foreign exchange market. In investigating revisions in forward rates as forecasts of future spot rates, we separate the effects of systematic optimism/pessimism from the effects of under/over- reaction to new information.

\section{Research Design and Data}

\section{A. Biased Forward Exchange Rates and Forecast Revisions}

Forward Rates as Unbiased Predictors of Future Spot Rates

Engel (1996) provides a comprehensive review of the literature on spot and forward exchange rate relationships. As Engel (1996) notes, with 
the assumption of rationality and risk neutrality, the forward exchange rate unbiasness is expressed as:

$$
E_{t}\left[S_{t+1}\right]=F_{t}
$$

which states the expected spot rate at $t+1$ conditional on the information available at time $t$ should be the same as the forward rate at time $t$. The hypothesis is usually expressed as the levels relationship:

$$
S_{t+1}=f_{t}+\zeta_{t+1}
$$

where $\zeta_{t+1}$ is a random variable (rational expectations forecast error) with $E_{t}\left[\zeta_{t+1}\right]=0$.

Two different regression equations have generally been used to test the hypothesis of unbiasness of forward exchange rates. The first one is the "levels regression":

$$
S_{t+1}=\mu+\beta_{f} f_{t}+\mu_{t+1}
$$

where the null hypothesis requires that $\mu=0, \beta_{f}=1$ and $E_{t}\left[\mu_{t+1}\right]=0$. Studies using equation (2) have found varying estimates of $\beta_{f}$, some but not all of them close to 1 and, thus, there is mixed support for the unbiasness of forward rates. In testing the orthogonality condition $E_{t}\left[\mu_{t+1}\right]=0$, not rejecting the hypothesis is a test of forward market efficiency under- rational expectations and risk neutrality. Empirical evidence shows that $S_{t}$ and $f_{t}$ have unit roots, and the hypothesis of unbiasness requires that $S_{t+1}$ and $f_{t}$ be cointegrated with vector $(1,-1)$ and that the stationary, cointegrating residual $\mu_{t+1}$ satisfy $E_{t}\left[\mu_{t+1}\right]=0$. The second regression equation used to test this hypothesis is the "differences equation":

$$
\Delta S_{t+1}=\mu^{*}+\alpha_{s}\left(f_{t}-S_{t}\right)+\mu^{*}{ }_{t+1},
$$

where the null hypothesis requires that $\mu^{*}=0, \alpha_{s}=1$, and $E_{t}\left[\mu^{*}{ }_{t+1}\right]=0$. Empirical results based on the differences equation strongly reject the hypothesis of unbiased forward exchange rate forecast. The typical estimates of $\alpha_{s}$ across a wide range of currencies and sampling frequencies are significantly negative. This result is often referred to as the forward discount anomaly, or forward discount puzzle.

Zivot (2000) argues that the hypothesis of unbiased forward exchange rates requires not only that $S_{t+1}$ and $f_{t}$ be cointegrated and that the cointegrating vector be $(1,-1)$, but also that $S_{t}$ and $f_{t}$ be cointegrated 
and the cointegrating vector be $(1,-1)$. Zivot (2000) investigates the relationship between the two models of cointegration and argues that the simple model of cointegration between $S_{t}$ and $f_{t}$ captures the stylized facts of typical exchange rate data better than the simple model of cointegration between $S_{t+1}$ and $f_{t}$ and so serves as a natural starting point for the analysis of exchange rate behavior. This conclusion implies that standard VAR methods are not appropriate for modeling the cointegrating vector of $\left(S_{t+1}, f_{t}\right)$, and the use of such methods can lead to erroneous inferences regarding the unbiasness hypothesis regarding the forward rate as a forecast of the future spot rate. Zivot (2000) confirms the contention in Baillie (1989), who points out VAR is misspecified considering the cointegration of spot rate and forward rate, and an error correction term needs to be added.

\section{Test for Rationality of Forward Rates as Spot Rate Forecasts}

MacDonald and Taylor (1992) review the literature on exchange rate determination and tests of the rationality of forward expectations. Expectations have been measured directly based on surveys (Cavaglia et al. [1994]) or indirectly based on an asset pricing model. Generally the traditional orthogonality test for rationality is tested in the regression:

$$
S_{t+k}-E_{t}\left[S_{t+k}\right]=\alpha_{1}+\beta_{1}\left({ }_{t} F_{t+k}-S_{t}\right)+v_{t+k}
$$

where the left-hand side is the exchange rate forecast error. The null hypothesis of rational expectations implies that $\alpha_{1}=0$ and $\beta_{1}=0$. In Cavaglia et al. (1994), the orthogonality regression was fitted via $O L S$ for each currency and for each forecast horizon, standard errors are corrected to allow for a $k-1$ order moving average. The findings reject the forward exchange rate as an unbiased predictor of the future spot rate, and the bias in the forward rate is attributed to both irrational expectations and a risk premium. Froot and Frankel (1989) analyze survey data on exchange rate expectations and show that not all the biases in the forward discount are due to time varying risk premia and at least some bias may be attributable to systematic expectational errors in that changes in the forward discount reflect changes in expected depreciation with the market risk premium constant.

In this paper we not only test the rationality of the forward rate as a forecast of the future spot rate, but we also examine how new information is incorporated in changes in the forward rate as the forecast period shortens and new information becomes available. We 
test if these revisions in the forward rate forecast of the future spot rate are characterized by systematic behavioral biases of under/overreaction and optimism and pessimism.

\section{B. Rationality, Under-or Over-Reaction and Pessimism vs. Optimism}

Assume at time $t-1$, market participants form the forecast of the future spot rate at times $t$ and $t+1$, which are the forward rates ${ }_{t-1} F_{t}$ and ${ }_{t-1} F_{t+1}$ respectively. At time $t$, market participants learn that their prior expectation (formed at $t-1$ ) is not accurate and they use the forecast error as part of the new information to revise their forecast for $t+1$. Market participants revise their forecast of the future spot rate for time $t+1$ (originally formed at time $t-1$, and reflected in the forward rate $\left.{ }_{t-1} F_{t+1}\right)$, and now form a new expectation for the spot rate at $t+1$, the forward rate ${ }_{t} F_{t+1}$. This paper focuses on the relationship between the forecast revision, ${ }_{t} F_{t+1}-_{t-1} F_{t+1}$ and the forecast error, ${ }_{t} F_{t+1}-S_{t+1}$. Before investigating the belief revision process, in this paper we check the stationarity of each time series.

Consider two behavioral factors that influence a forecast and revisions to such forecasts with the arrival of new information: optimism versus pessimism and over-reaction versus under- reaction. Forecasters are optimistic when their forecast errors tend to be positive and are pessimistic when the errors are negative. If forecasters over-react to new information, then their forecast revisions are positive and their errors are negative or when their revisions are negative and their errors are positive. In other words, forecasters overreact when their revisions and errors are of the opposite signs. Similarly, they under-react when their revisions and errors are of the same sign. In order to distinguish between the effects of optimism/pessimism from the effects of over/under reaction more formally, forecast errors are regressed on forecast revisions. Assume forecast error for time $t$ is $F E_{t}$ $={ }_{t} F_{t+1}-S_{t+1}$, and the forecast revision for time $t$ is $F R_{t}={ }_{t-1} F_{t+1}{ }_{t} F_{t+1}$, the regression is:

$$
F E_{t}=\alpha+\beta F R_{t}+\mu_{t}
$$

The null hypothesis of rationality is $\alpha=\beta=0$. Positive $\alpha$ implies optimism, while negative $\alpha$ implies pessimism. Positive $\beta$ implies over-reaction and negative $\beta$ implies under-reaction to new information. A finding of negative beta would be consistent with the widely replicated and accepted bias of conservatism (Shiller [2002]). Tables 1a 
and $1 \mathrm{~b}$ report the descriptive statistics for $F E$ and $F R$ for each currency. While the mean forecast errors are almost uniformly negative, there do not seem to be any major surprises in these tables.

\section{Impact of Prior Period Changes}

Under- or Over-reaction: In order to assess systematic over- or under-reaction to information in forward rates as forecasts of future spot rates, we first examine whether the prior period spot rate change would have any effect on the forecast error and we run the following regression for each currency: ${ }^{1}$

$$
F E_{t}=\alpha_{0}+\alpha_{1} P S C H_{t-1}+e_{t} \text {, }
$$

where $F E_{t}$ is the time $t$ forecast error, and $P S C H_{t}$ is the prior spot rate change $\left(S_{t-1}-S_{t-2}\right){ }^{2}$ The estimated slope for regression (6) should indicate if the forward rate forecasts are under- (positive coefficient) or over-reactions (negative coefficient) to prior changes in the spot rate.

Systematic pessimism versus optimism: The results from the above regressions, however, do not allow us to separate under- or over-reaction from optimism or pessimism in the foreign exchange markets. For example, a positive coefficient can result from under-reaction to new information or from systematically optimistic forecasts. In order to differentiate between these effects (under- or over-reaction versus optimism or pessimism), we group our observations into high, low, and medium changes of how prior changes impact forecasted changes in exchange rates:

$$
\begin{gathered}
\text { PredCh }=\alpha_{0}+\alpha_{1} \text { LoPSCH }_{t-1}+\alpha_{2} \text { HiPSCH }_{t-1} \\
+\alpha_{3} \text { PSCH }_{t-1}+\alpha_{4} \text { DLPSCH }_{t-1}+\alpha_{5} \text { DHPSCH }_{t-1}+e_{t .},
\end{gathered}
$$

1. We follow Easterwood and Nutt (1999) in attempting to examine whether forward foreign exchange markets are systematic optimistic or systematic pessimistic.

2. One possible shortcoming of this regression is that the independent variable may contain both the expected and unexpected components of the spot rate change. To single out the effect of the unexpected change in spot rate, one additional regression is used to supplement the above forecast regression. In this additional regression, the independent variable is changed to reflect the unexpected change in the prior spot rates $U P C H_{t-1}$, which is $P_{S C H}$ minus the average change of the prior 3-month spot rates. However, this change does not result in any changes in the conclusions and the results are not reported here but are available from the authors. 
where PredCh is the predicted change of the future spot rate defined as the ${ }_{t-1} F_{t}-S_{t-1}$, and $P S C H_{t-1}$ is the prior spot rate change $\left(S_{t-1}-S_{t-2}\right)$. We define two dummy variables, $\mathrm{LOPSCH}_{t-1}$ and $\mathrm{HiPSCH}_{t-1}$, that equal one if $\mathrm{PSCH}_{t-1}$ is in the lower or upper quartile respectively for changes in exchange rates $P S C H_{t-1}$, and 0 otherwise. These two dummy variables are also included as the interactive term between $P S C H_{t-1}$ and LoPSCH$_{t-1}$ and $\mathrm{HiPSCH}_{t-1}$ so that $D L P S C H_{t-1}$ equals $P S C H_{t-1}$ times $\mathrm{LoPSCH}_{t-1}$, and $\mathrm{DHPSCH} \mathrm{H}_{t-1}$ equals $\mathrm{PSCH}_{t-1}$ times $\mathrm{HiPSCH}_{t-1}$.

In this regression estimate, $\alpha_{3}$ measures the impact for the middle two quartiles while the composite coefficient $\alpha_{3}+\alpha_{4}$ represents the impact for the lower quartile and $\alpha_{3}+\alpha_{5}$ represents the impact for the upper quartile. If there is systematic pessimism, forecasts should over-react to lower quartile changes (have a negative coefficient) and under-react to upper quartile changes (have a positive coefficient). The opposite signs in this set of coefficients would indicate systematic optimism. Thus, this specification should allow us to assess both the under- or over-reaction effect as well as the pessimism or optimism effects.

\section{Forecast Revisions}

In addition to estimating one-period forecasts, we extend our study to include two periods and examine the effect of forecast error on the revision of traders' forecasts. Forecast revision is defined as $F R_{t}=$ ${ }_{t-1} F_{t-{ }_{t-2}} F_{t}$. We estimate the following regression:

$$
\begin{aligned}
& F R_{t}=\beta_{0}+\beta_{1} L o F E_{t-1}+\beta_{2} H i F E_{t-1}+\beta_{3} F e_{t-1} \\
& +\beta_{4} D L F E_{t-1}+\beta_{5} D H F E_{t-1}+e_{t},
\end{aligned}
$$

where $F e_{t-1}$ is the prior period forecast error. ${ }^{3}$ Once again, we define two dummy variables, $L o F E_{t-1}$ and $H i F E_{t-1}$ that equal one if $F e_{t-1}$

3. It is possible to divide the over-reaction conditions into two further categories. Some cases of over- reaction can be re-classified as mis-reactions. Mis-reaction occurs when, in some cases, the forecast revision is excessive with respect to the two-period forecast error. This can happen when the forecast revision, the second period forecast error, and the two period forecast error are all positive or are all negative. In such cases, the forecast revision is in the wrong direction with respect to the two period forecast error, i.e., the difference between the $t-2$ forward rate for time $t$ and the future spot rate for time $t$. As a robustness check, we estimate our main regression excluding the observations reflecting mis-reaction. Though the results are not reported in this paper, our conclusions in this paper hold and are actually strengthened when excluding the mis-reaction observations from our data. 


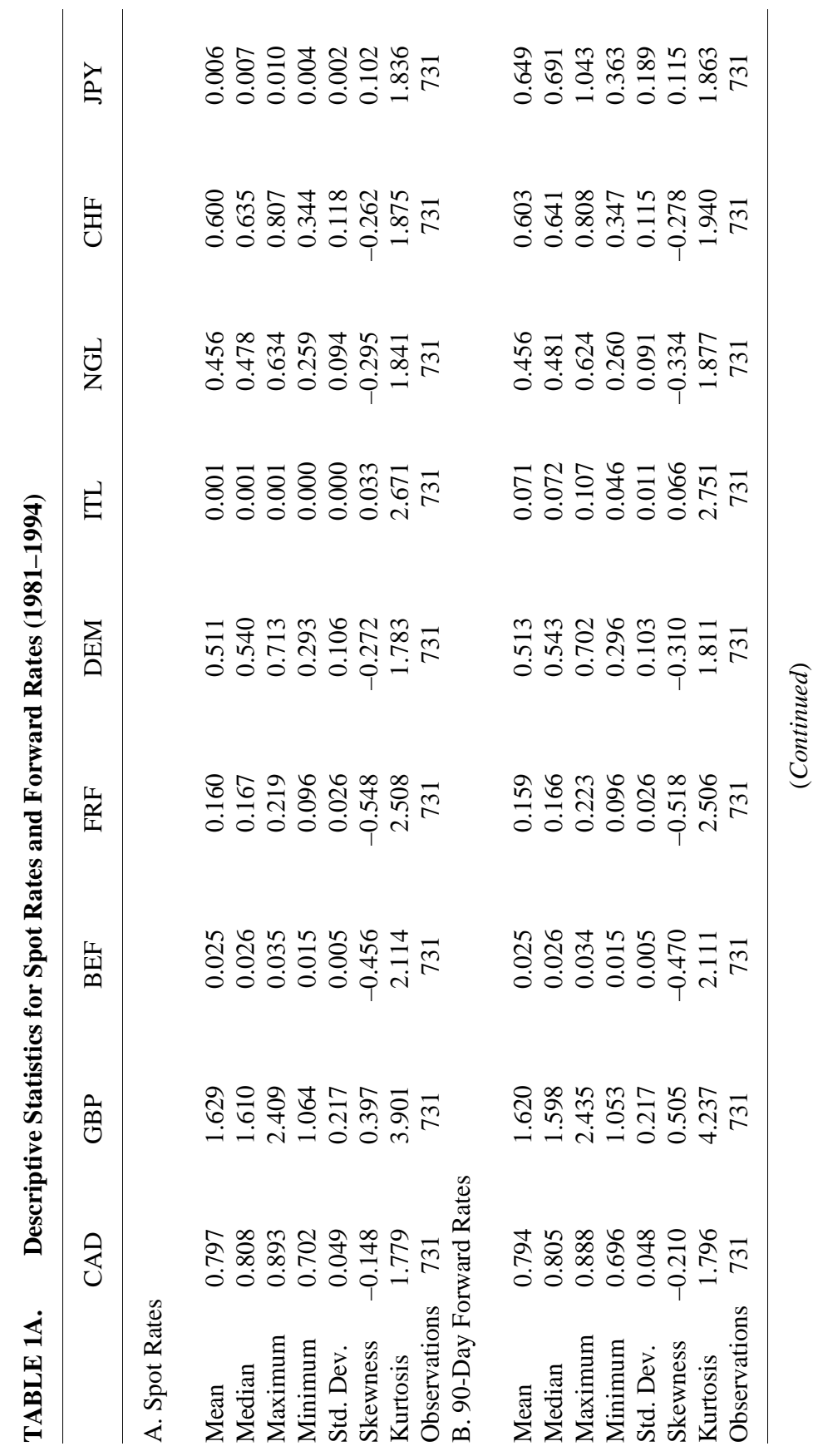




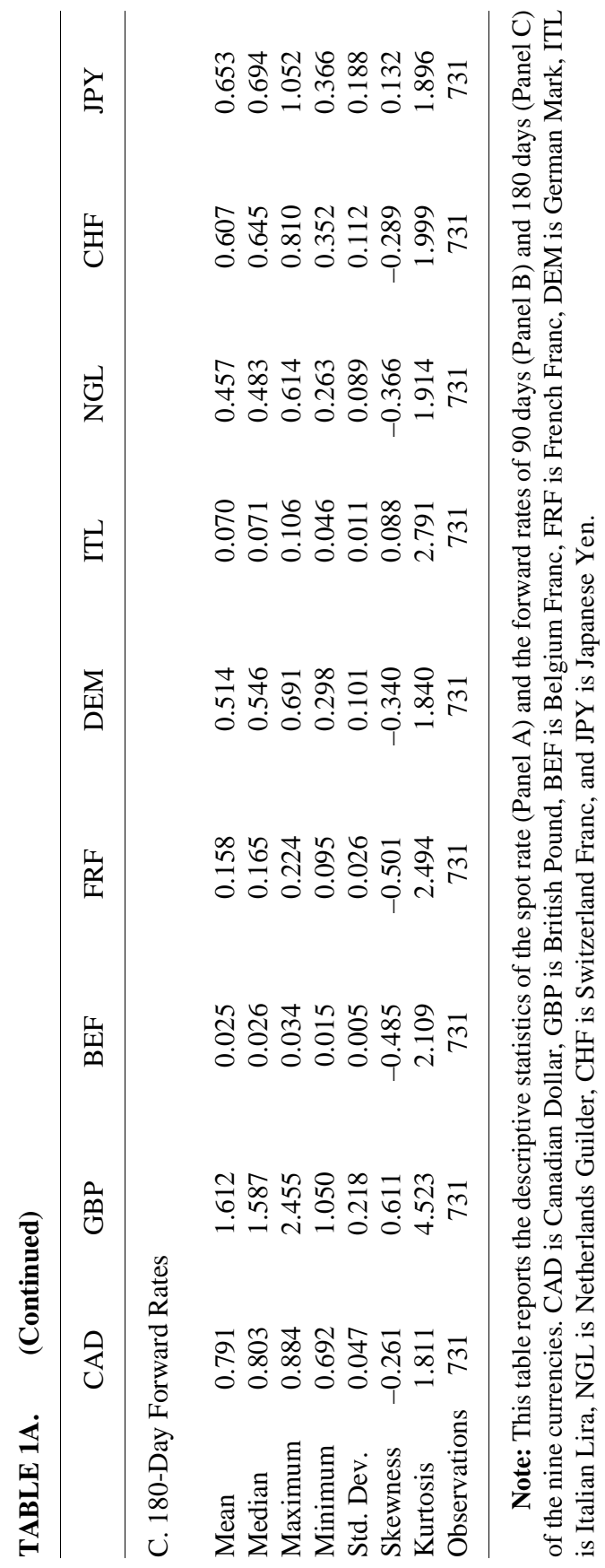




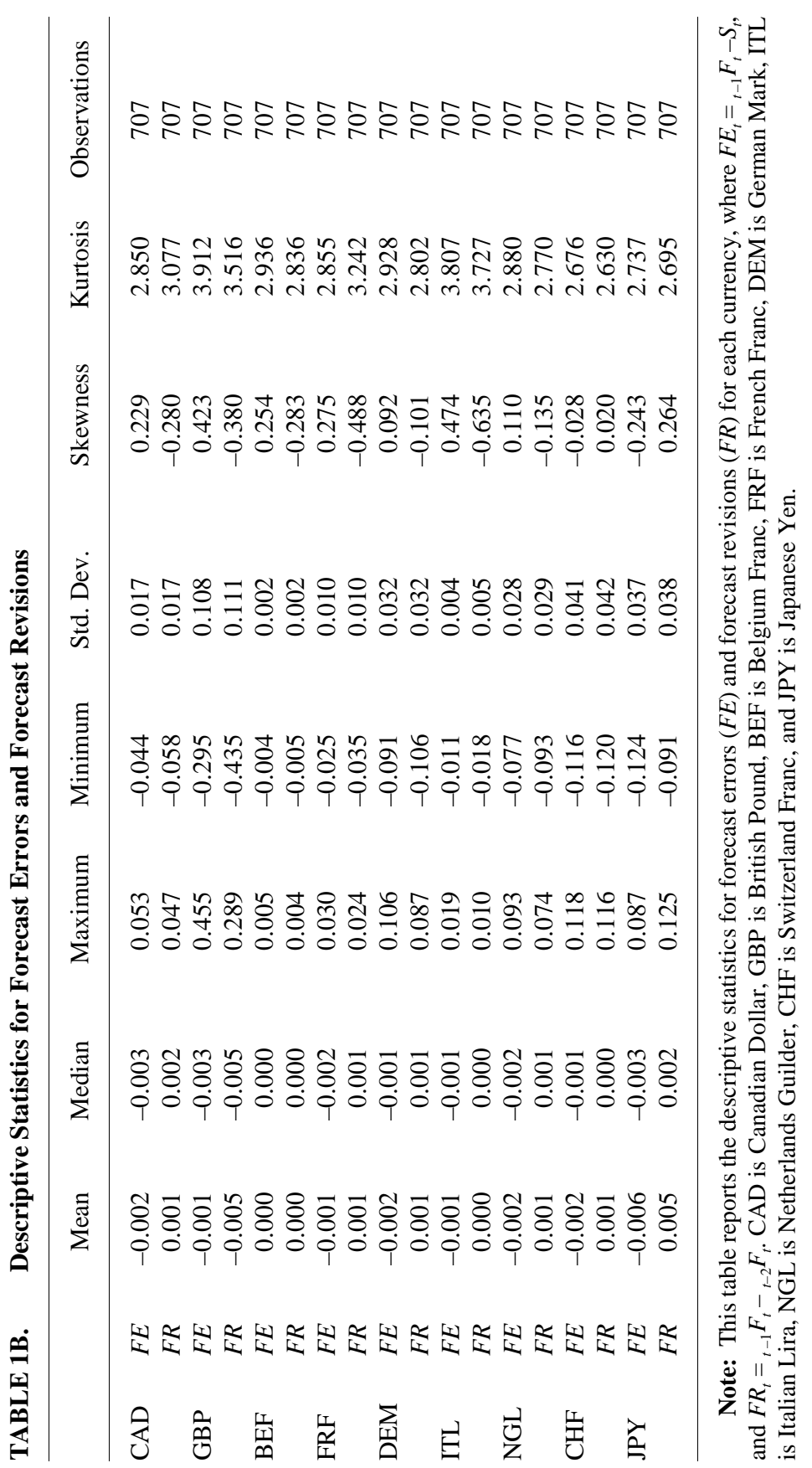




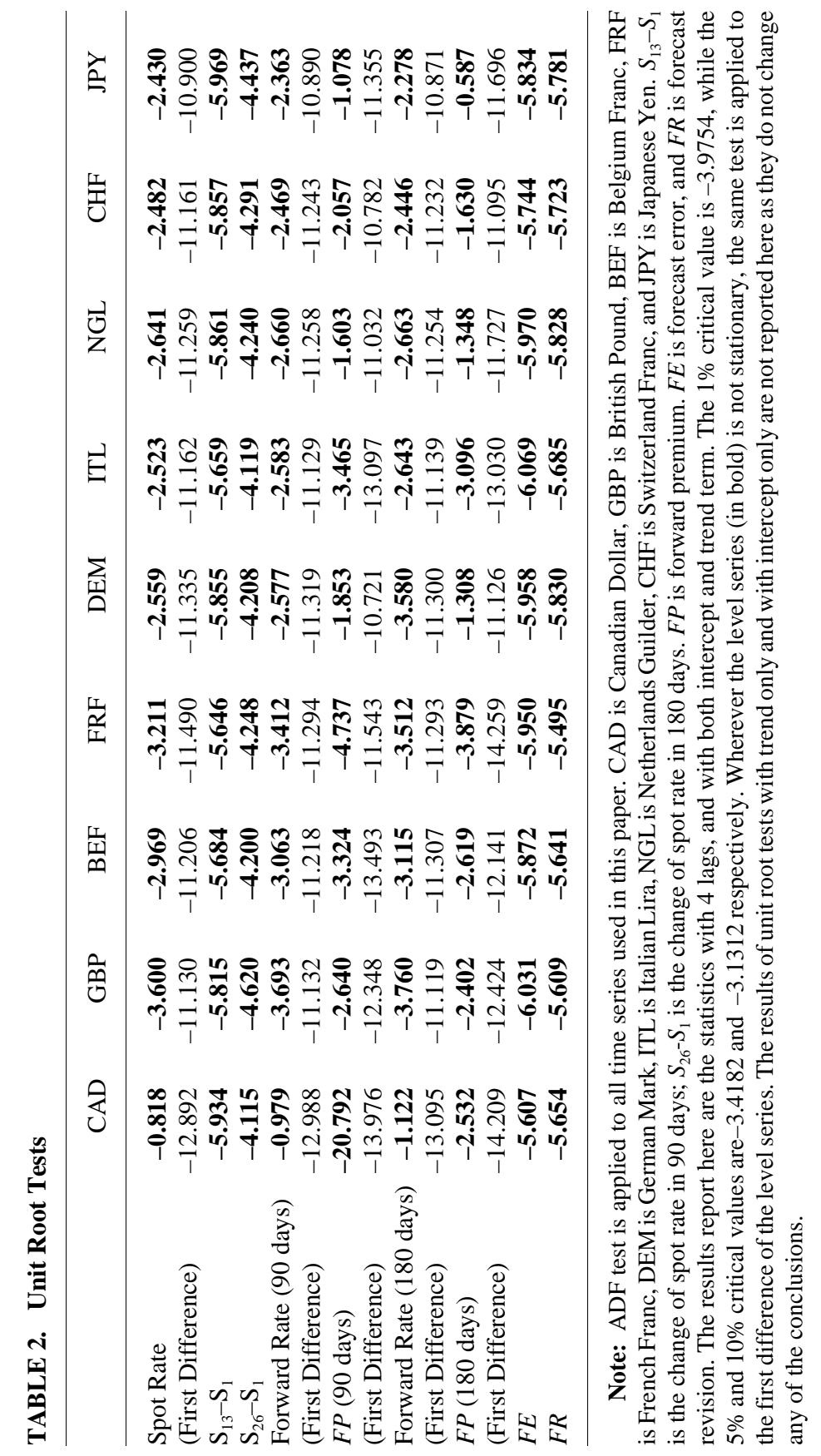


isrespectively in the lower or upper quartile, and 0 otherwise. These two dummy variables are also included as interactive terms between $F e_{t-1}$ and $L o F E_{t-1}$ and $H i F E_{t-1}$. DLFE $E_{t-1}$ equals $P S C H_{t-1}$ times $L o F E_{t-1}$, and $D H F E_{t-1}$ equals $F e_{t-1}$ times $H i F E_{t-1}$. If the foreign exchange markets under-react to information, the slope coefficients should be positive and negative if over-reaction holds. Finally, if traders are systematically optimistic, then $\beta_{3}+\beta_{4}$ should be positive and $\beta_{3}+\beta_{5}$ should be negative.

\section{Data}

The data cover the currencies of the ten major industrialized countries, United States, Canada, United Kingdom, Germany, France, Italy, Netherlands, Switzerland, Belgium, and Japan. Weekly spot and 180 and 90-day forward exchange rate data for 1981-1995 for the nine currencies against the U.S. dollar are obtained from the Harries Bank Weekly Review. ${ }^{4}$ Table 1a reports the descriptive statistics for the data set. Three weekly closing exchange series are contained in the dataset, which are the spot rate, 90-day forward rate, and the 180-day forward rate. ${ }^{5}$ All reported rates are in U.S.D. per foreign currency unit and the descriptive statistics are provided in table 1a. This data set contains 731 observations for each currency covering 14 years (1981-1994).

\section{Empirical Results}

\section{A. Preliminary Analysis}

Table 2 reports the results of the tests for unit roots in each of the time series including the spot rate, forward rates for 90 and 180 days, forward premium for 90 and 180 days, changes in spot rates for 90 days and 180 days, and also the forecast error and forecast revision. From table 2, we can see that, with the only exception of 90-day forward rate of the French Franc, all spot rates, forward rates, and forward premiums have unit roots in the level series and become stationary for first differences. Similarly, changes in spot rates, forecast errors and forecast revisions are also stationary.

4. As compiled by Professor Richard M. Levich of N Y U and provided to the authors.

5. The reported spot rate and forward rates in all tables for Italian Lira and Japanese Yen are the original value multiplied by one hundred. 
Cointegration tests of the spot and 90-day forward rate, and the spot and 180-day forward rate for each currency are in table 3. Unlike Zivot (2000), we do not find the cointegrating vector $[1,-1]$ for about half the currencies. This finding is not unusual. As summarized in Engel (1996), some studies find that the spot and the forward rate are cointegrated with the cointegrating factor $[1,-1]$, other studies find they are cointegrated but the cointegrating vector is not $[1,-1]$, and still others find they are not cointegrated.

To obtain a preliminary assessment of the relationship between the forecast error and the forecast revision, this paper examines subgroups when observations are grouped according to the signs of the forecast revisions and the signs of the forecast errors. Table 4 presents these results and reports the number of observations in each group and the percentage of each group in the total observations (707) for each currency. The over- and under- reaction columns reflect respectively the sums of the columns with different signs for $F R$ and $F E(F R<0$ with $F E>0$ and $F R>0$ with $F E<0)$ and the same signs for $F R$ and $F E(F R<0$ with $F E<0$ and $F R>0$ with $F E>0$ ).

As seen in table 4, the patterns observed for the totals are also reflected in the case of each currency. The totals for positive FEs (optimism) are lower (46\% versus 54\%) and on average these foreign exchange markets exhibit pessimism. The totals for the over- and underreaction columns (42\% versus 58\%) seem to suggest that foreign exchange investors and markets tend on average to under- react to new information. Overall, these preliminary results indicate that participants in the foreign exchange markets tend to be somewhat pessimistic and generally under-react to new information.

\section{B. Under-versus Over-Reaction}

This section reports table 5, 6 and 7 results of the more formal tests designed to assess over- versus under-reaction in foreign exchange markets. Table 5 reports the results of estimating equation (6). The coefficients of $\mathrm{PSCH}_{t}$ for all currencies are statistically significantly positive. Using the unexpected prior period change in exchange rates as the independent variable gives similar results also with significant positive slope coefficients. The positive slope coefficients in these regressions indicate that the forward rates do not reflect all of the expected changes, that is they under-react to information in prior changes in the spot rate. 


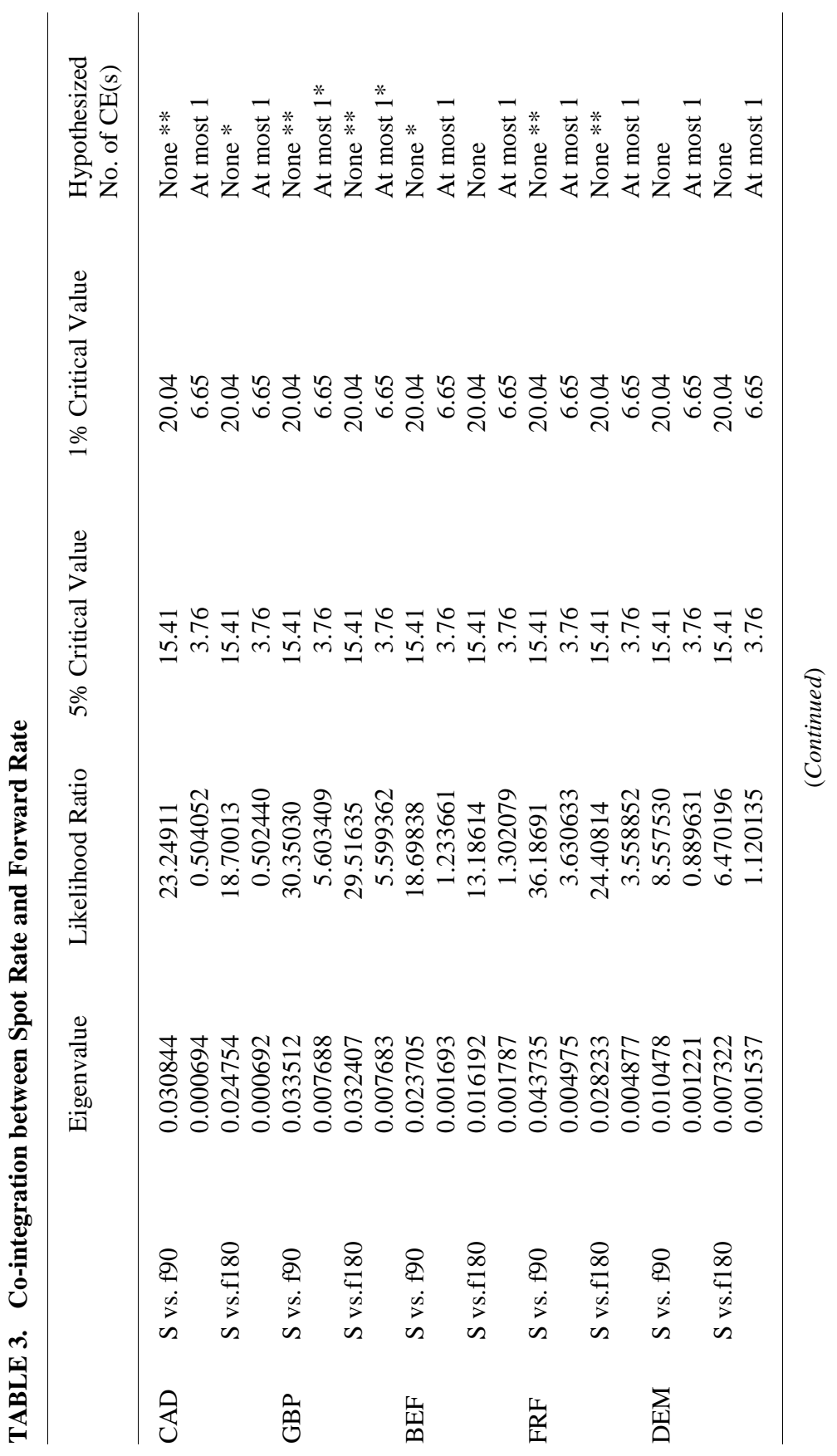




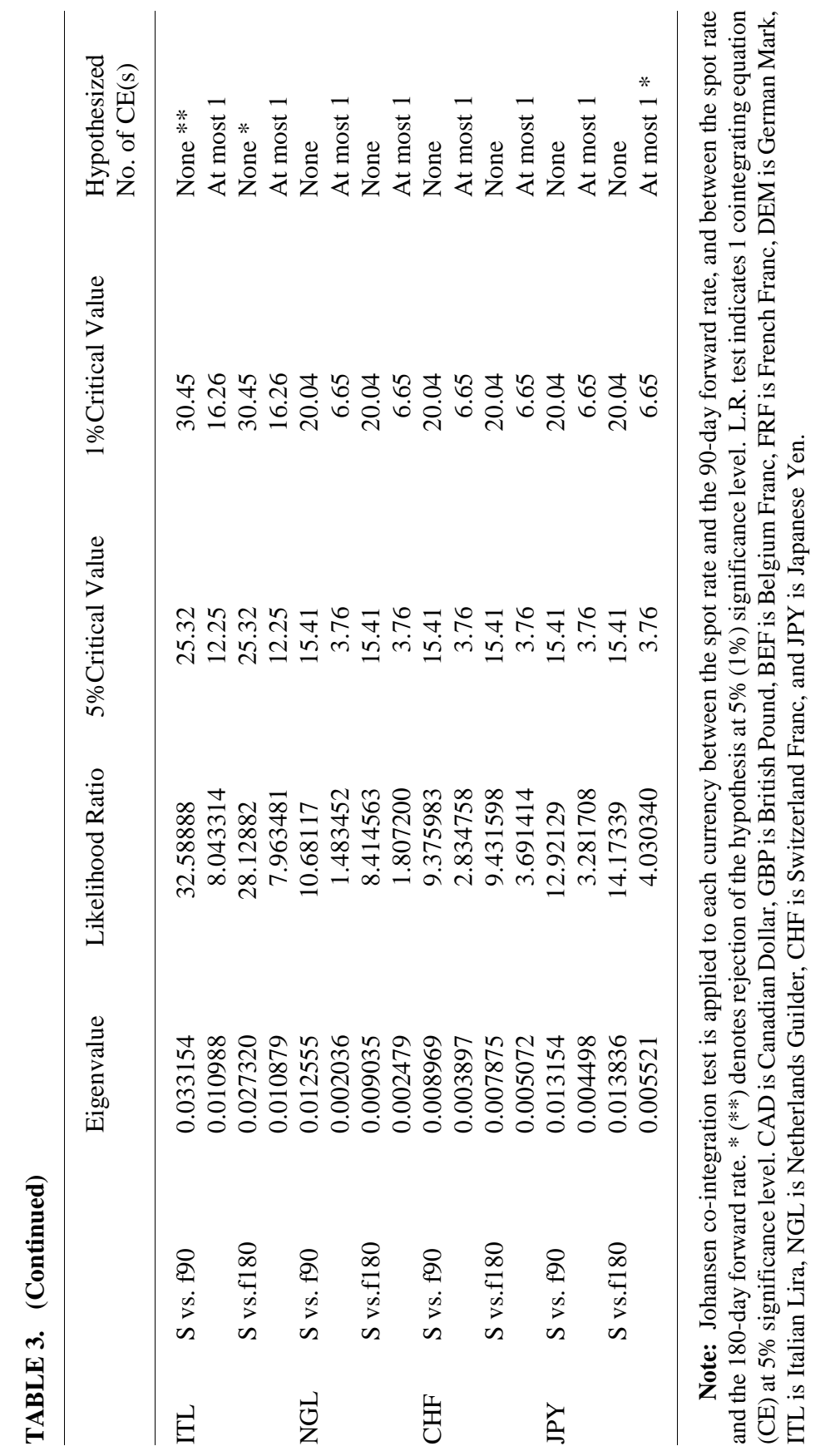




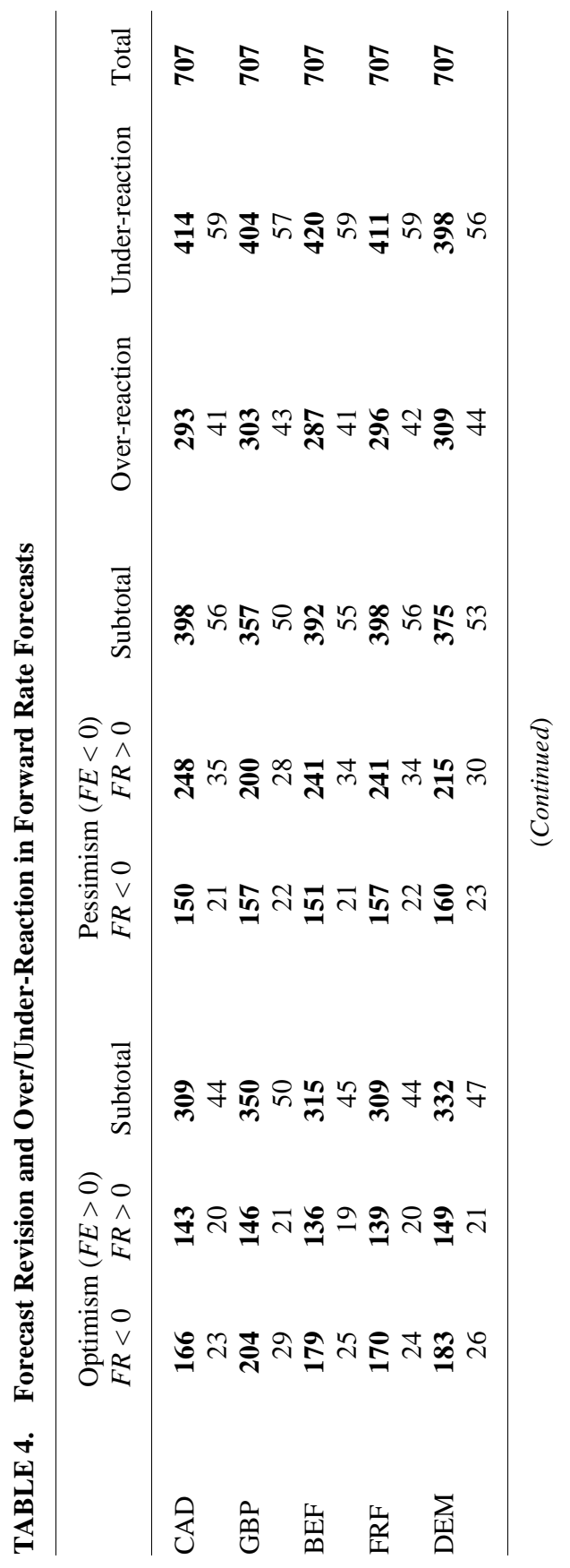




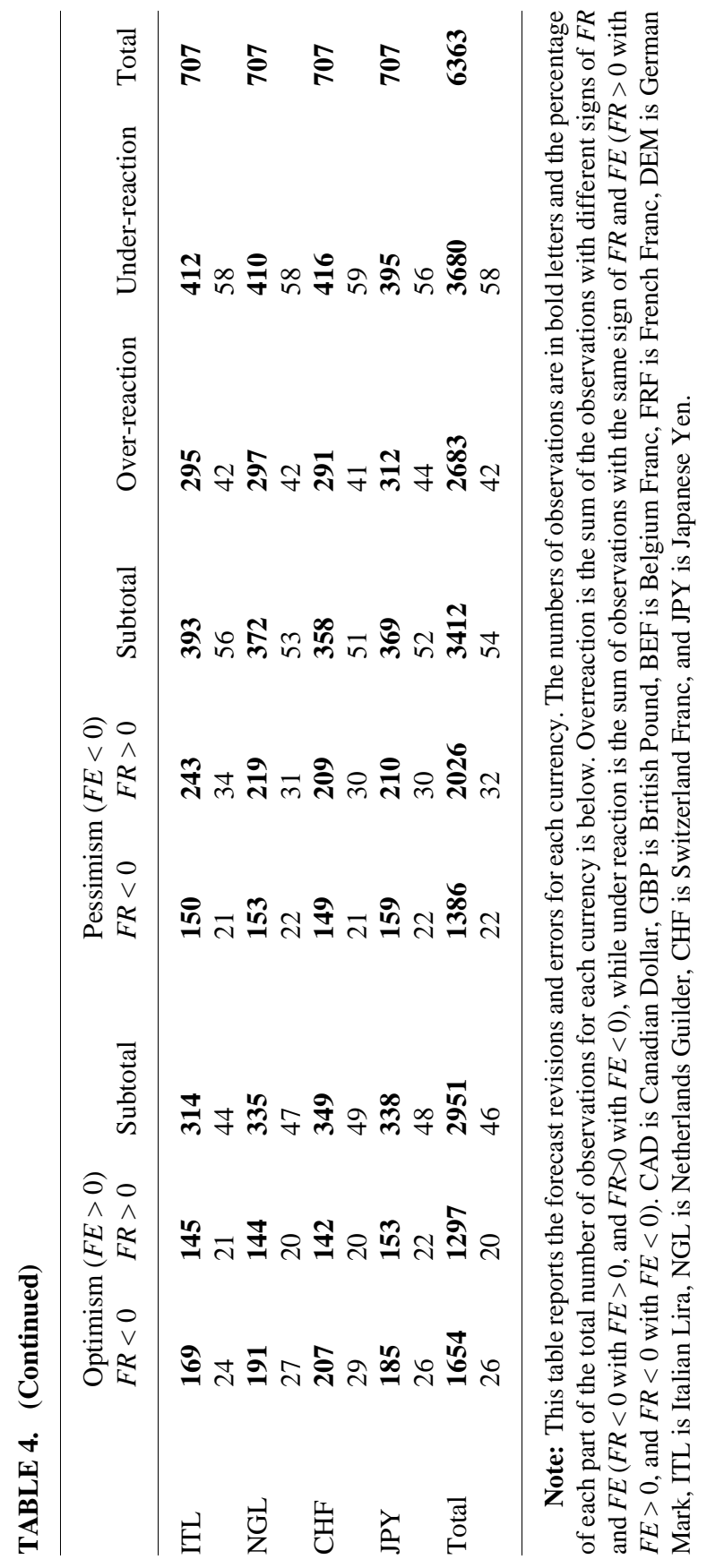




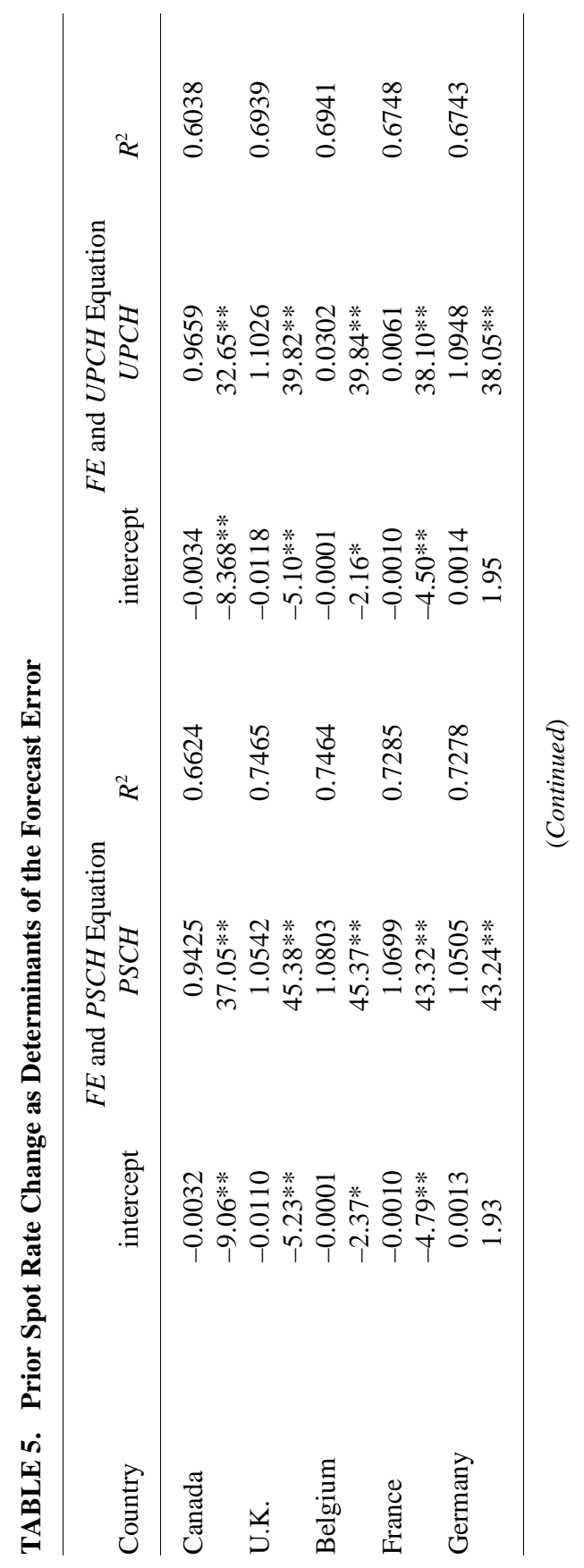




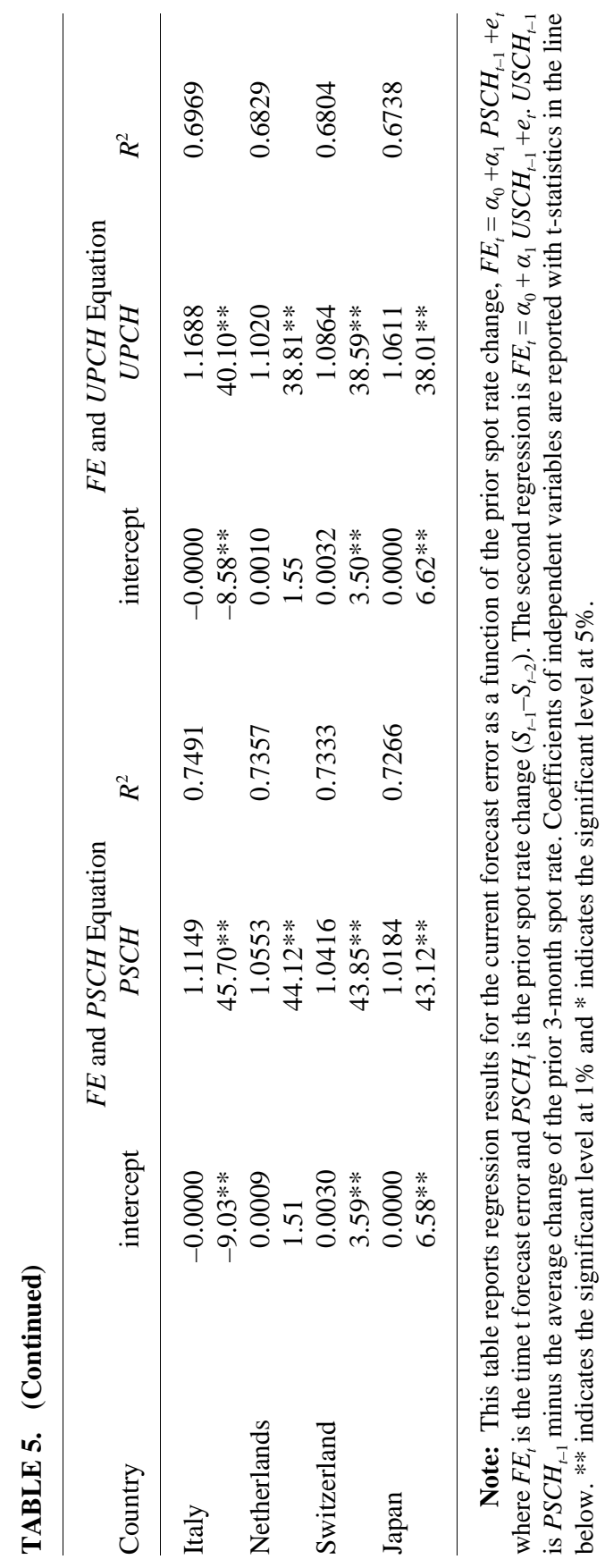




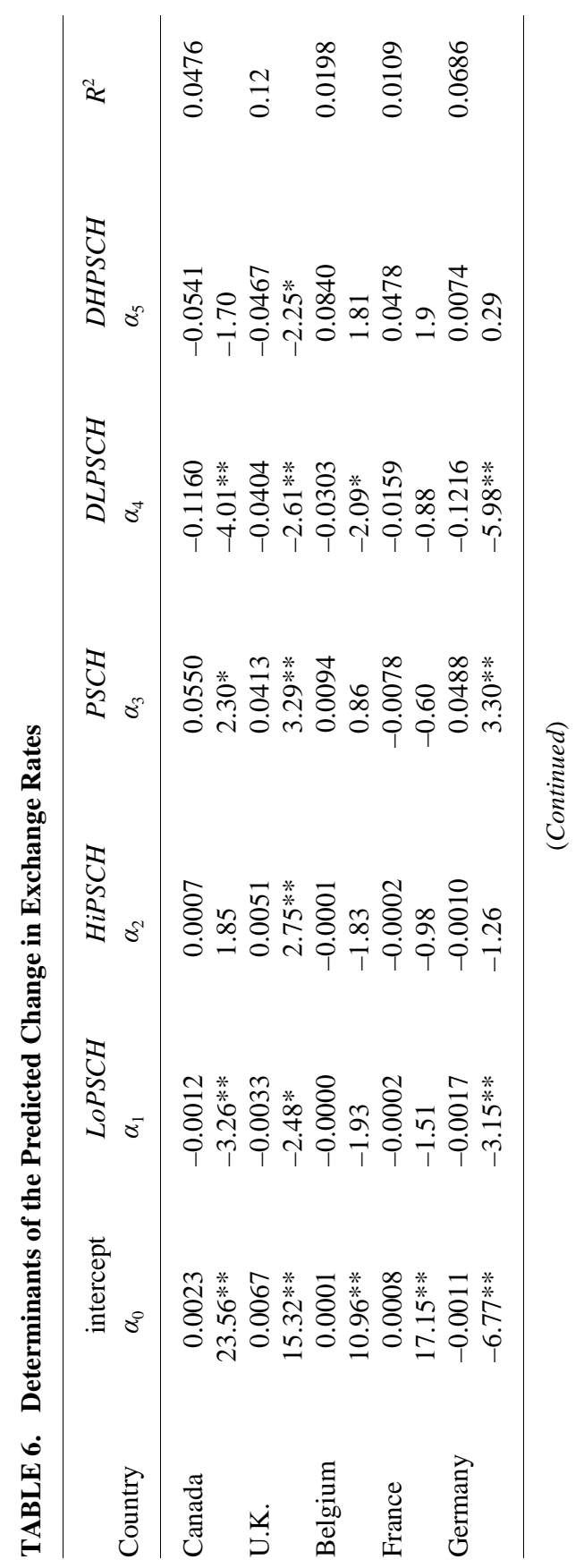




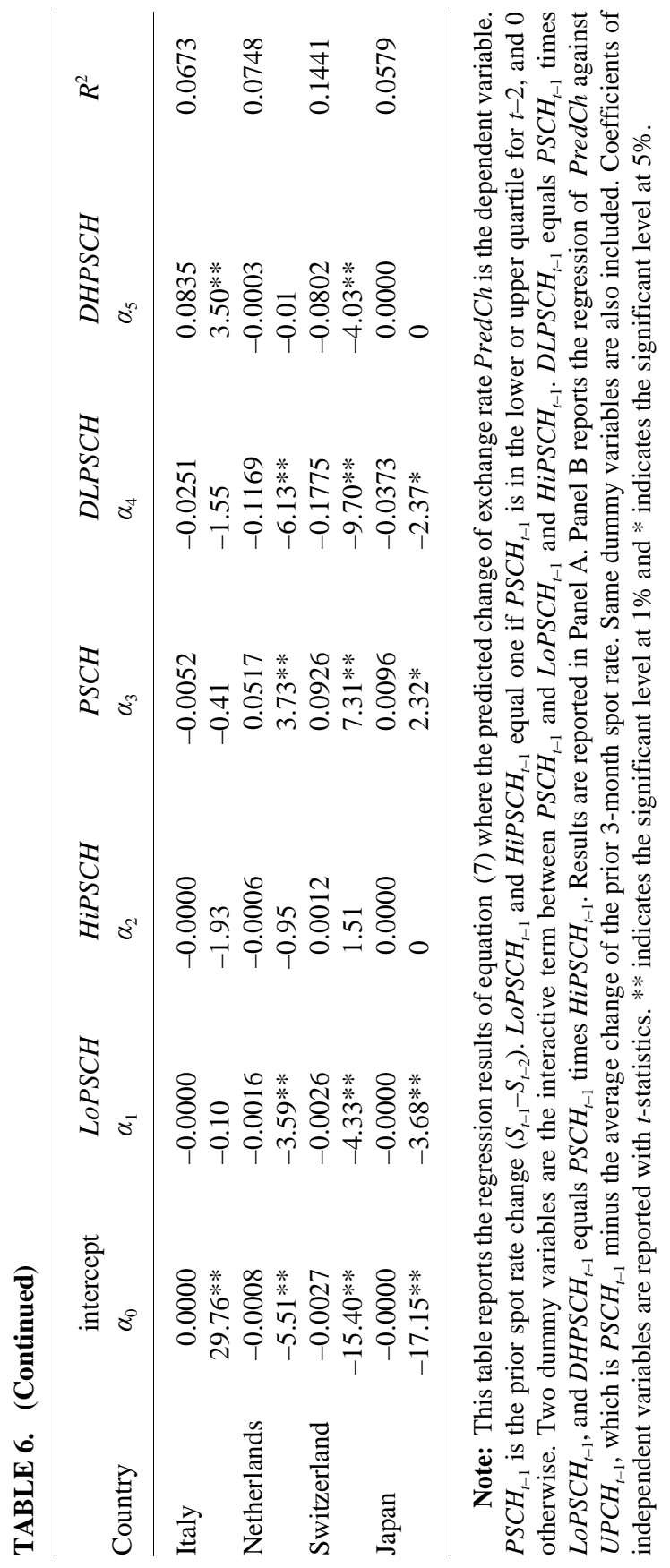




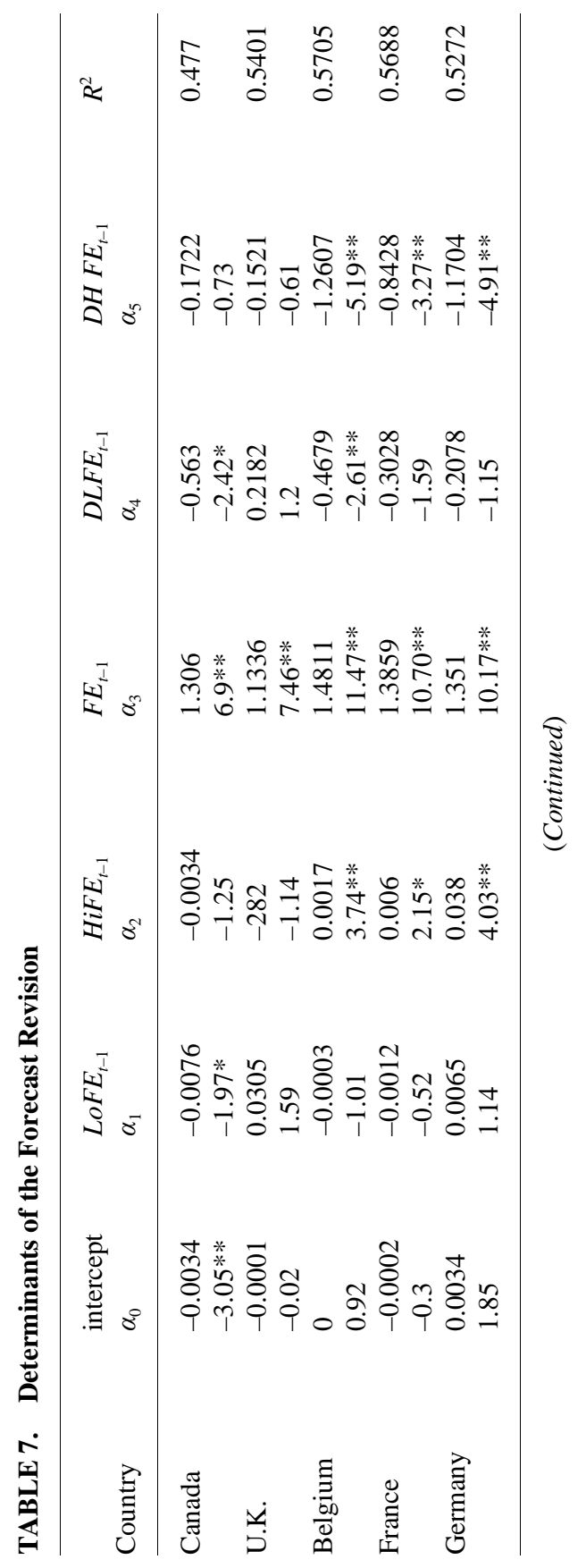




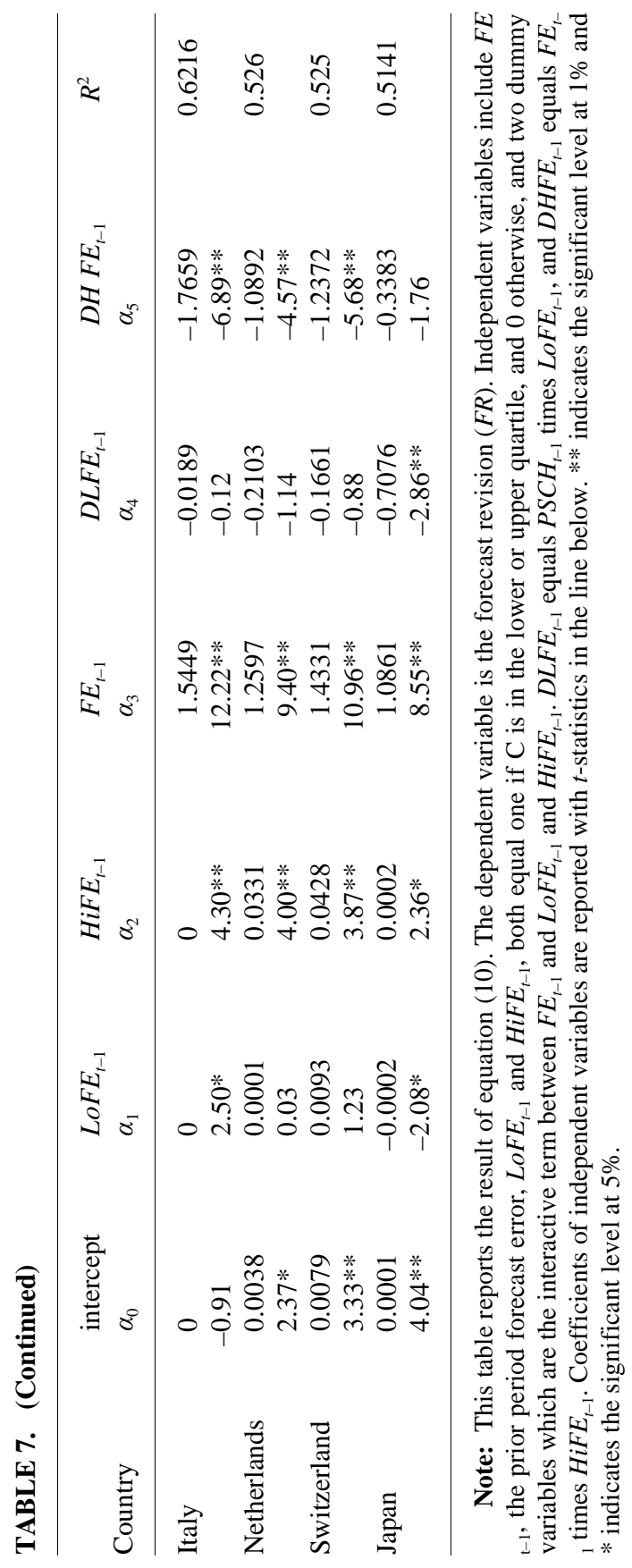


TABLE 8. Forecast Error and Forecast Revision Regressions- Pooled Set

\begin{tabular}{lccc}
\hline & Pooled Dataset & Over-reaction & Under-reaction \\
\hline Intercept & $\mathbf{- 0 . 0 0 2}$ & $\mathbf{- 0 . 0 0 1}$ & $-\mathbf{0 . 0 0 3}$ \\
& $-3.443^{* *}$ & $-2.049^{*}$ & $-5.108^{* *}$ \\
$F R$ & $\mathbf{- 0 . 1 2 2}$ & $\mathbf{0 . 6 4 6}$ & $\mathbf{- 0 . 6 4 3}$ \\
& $-10.02^{* *}$ & $42.280^{* *}$ & $-56.439^{* *}$ \\
Adjusted $R^{2}$ & $\mathbf{0 . 0 1 5}$ & $\mathbf{0 . 4 0 0}$ & $\mathbf{0 . 4 6 4}$ \\
Observations & $\mathbf{6 3 6 3}$ & $\mathbf{2 6 8 4}$ & $\mathbf{3 6 7 9}$ \\
\hline
\end{tabular}

Note: This table reports regression results for $F E_{t}=\alpha+\beta F R_{t}+\mu_{t}$ for the pooled dataset. $F E$ is forecast error and $F R$ is forecast revision. The null hypothesis of rationality requires $\alpha=\beta=0$. Coefficients (in bold) and $t$-statistics (below them) are reported, as well as the adjusted $R$ squares and number of observations (both are in bold). The pooled dataset is further divided into subgroups of over and under reaction. Overreaction is the sum of the observations with different sign of $F R$ and $F E$ ( $F R<0$ with $F E>0$, and $F R>0$ with $F E<$ 0 ); under reaction is the sum of observations with the same sign of $F R$ and $F E$ ( $F R>0$ with $F E>0$, and $F R<0$ with $F E<0$ ).

Table 6 reports the results of the regressions for equation 7 for the impact of prior period changes on predicted exchange rate changes for all nine countries. These regressions evaluate the impact of prior changes in the extreme quartiles as well as for the two middle quartiles. As the results presented in the middle section of this table indicate, for the middle two quartiles, six of the prior change coefficients are significantly positive (the other three are not significant) indicating under-reaction and confirming the results presented in the prior table. In examining the first three columns of results in this table for the lower quartile, except for the U.K., the composite coefficients for the lower quartile are all negative (over-reaction) while the composite coefficients for the upper quartile are mostly positive (under-reaction). This combination of coefficients indicates systematic pessimism in the reaction of the forward rate to new information for seven of the nine exchange rates examined (the signs of the coefficients only for the U.K. pound indicate optimism but they are not significant). ${ }^{6}$

Table 7 reports results for the regressions for equation 8 that examine forecast revisions as reflected in changes in forward rates. As may be expected, last period forecast error seems to have a large and

6. Regressions using the unexpected prior period changes show similar results and are not presented here for brevity but are available from the authors. 
significant impact on the forecast revision since all of the coefficients are significantly positive and the $R^{2} \mathrm{~s}$ are generally high. Consistent with results in table 3, the coefficient of $F e_{t-1}$ are all positive for all nine currencies, indicating that the forward exchange rate systematically under-reacts to information. ${ }^{7}$

\section{Pessimism versus Optimism}

This section, and tables 8 and 9 report on the results of the more formal tests designed to assess pessimism versus optimism in foreign exchange markets. Table 8 reports the result of regressions of the pooled dataset and of the two subgroups, over-reactions and under-reactions. The null hypothesis of rationality requires both intercept and coefficient of $F R$ be zero in the regression, while positive $\alpha$ implies optimism, negative $\alpha$ implies pessimism, positive $\beta$ implies over-reaction, and negative $\beta$ implies under- reaction to new information. The regression results of pooled dataset indicate that rationality is clearly rejected. ${ }^{8}$ We find significant negative coefficients of both the intercept and $F R$, indicating non-rationality, pessimism, and under-reaction to new information.

Table 8 also presents the results for the two subgroups, over-reaction and under-reaction. ${ }^{9}$ Both the intercept terms are negative indicating pessimism in each case. As expected, the $\beta$ coefficient is positive for the over-reaction group and negative for the under-reaction group. As expected, the regression $R$-squares are much higher for the split samples.

Table 9 panel A reports the overall and subgroup (over- and underreaction) regression results for each currency. The results indicate that under-reaction with pessimism is a consistent pattern for all currencies and rationality is definitely rejected for all these currencies. As expected, for each currency, the coefficients for the over-reaction groups are positive while they are negative for the under-reaction groups. The intercept coefficient for each currency's under-reaction group is negative indicating pessimism uniformly. The intercept

7. The signs of the coefficients for the lower and upper quartiles do not indicate systematic pessimism or optimism in this case.

8. Since the pooled data set contains data for nine currencies and for 14 years, we may have a problem with time series cross-sectional cross-correlation in error terms, so we also estimate the regressions using the seemingly unrelated regression $(S U R)$ procedure to supplement our $O L S$ results. The two sets of results are very similar and give similar results.

9. When a dummy for over- and under-reaction is introduced in the pooled regression, it is highly significant and the other coefficients remain significant. 


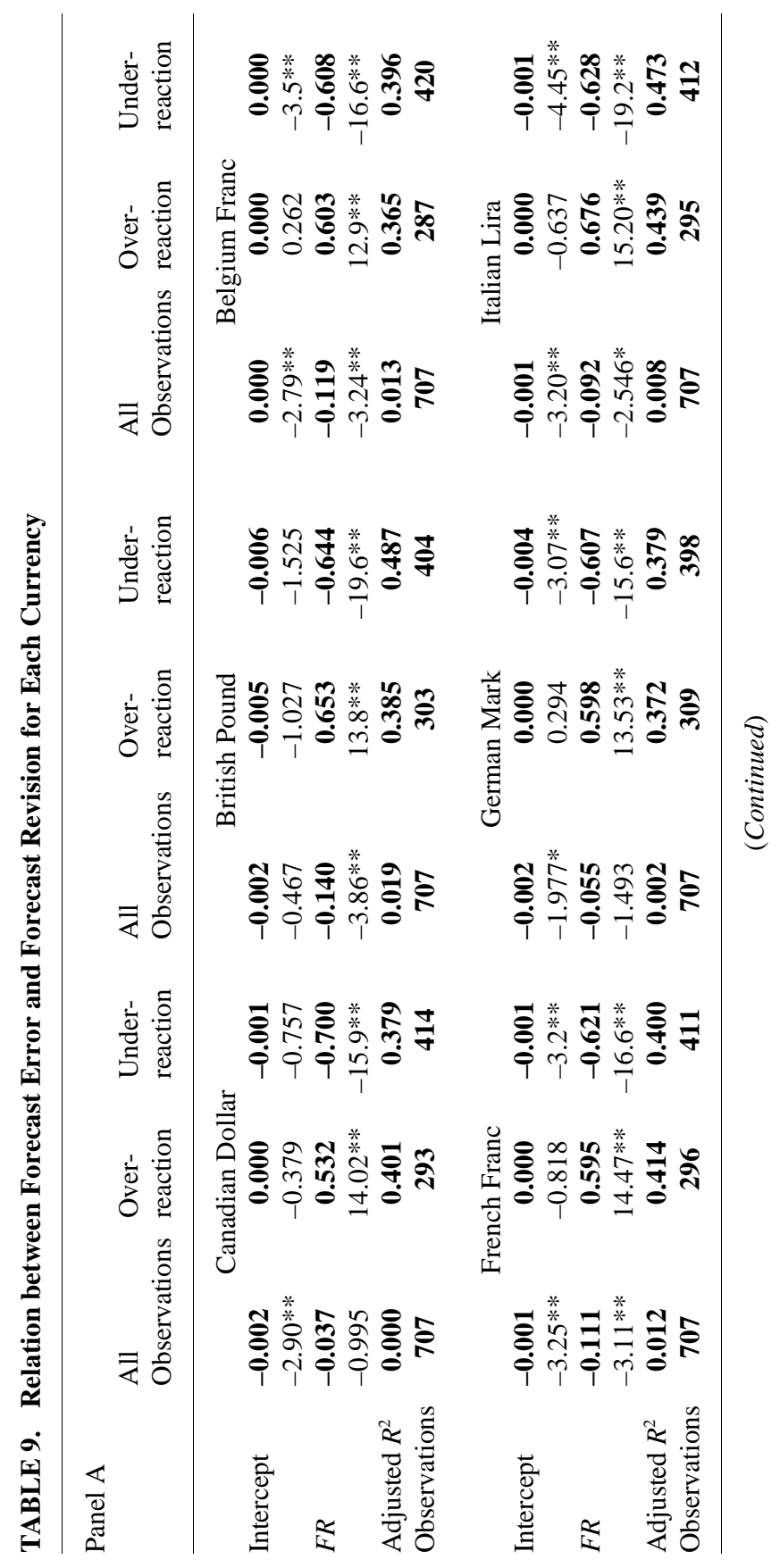




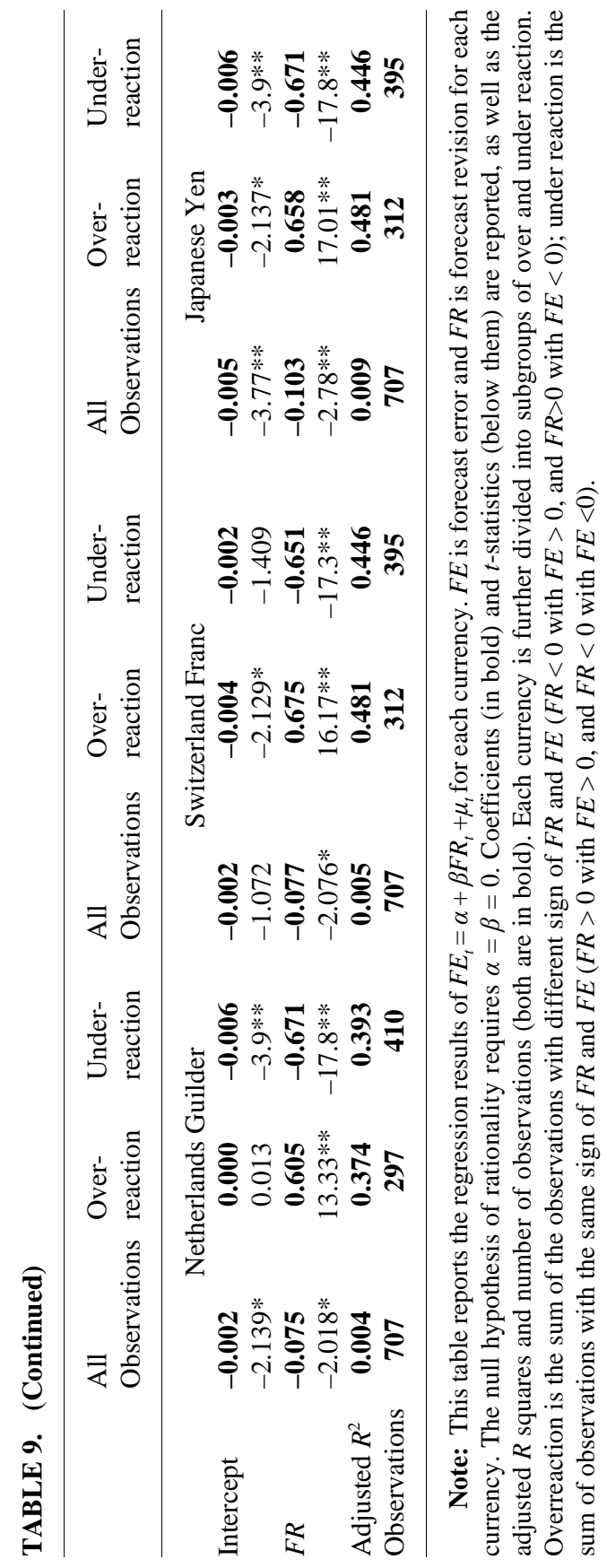




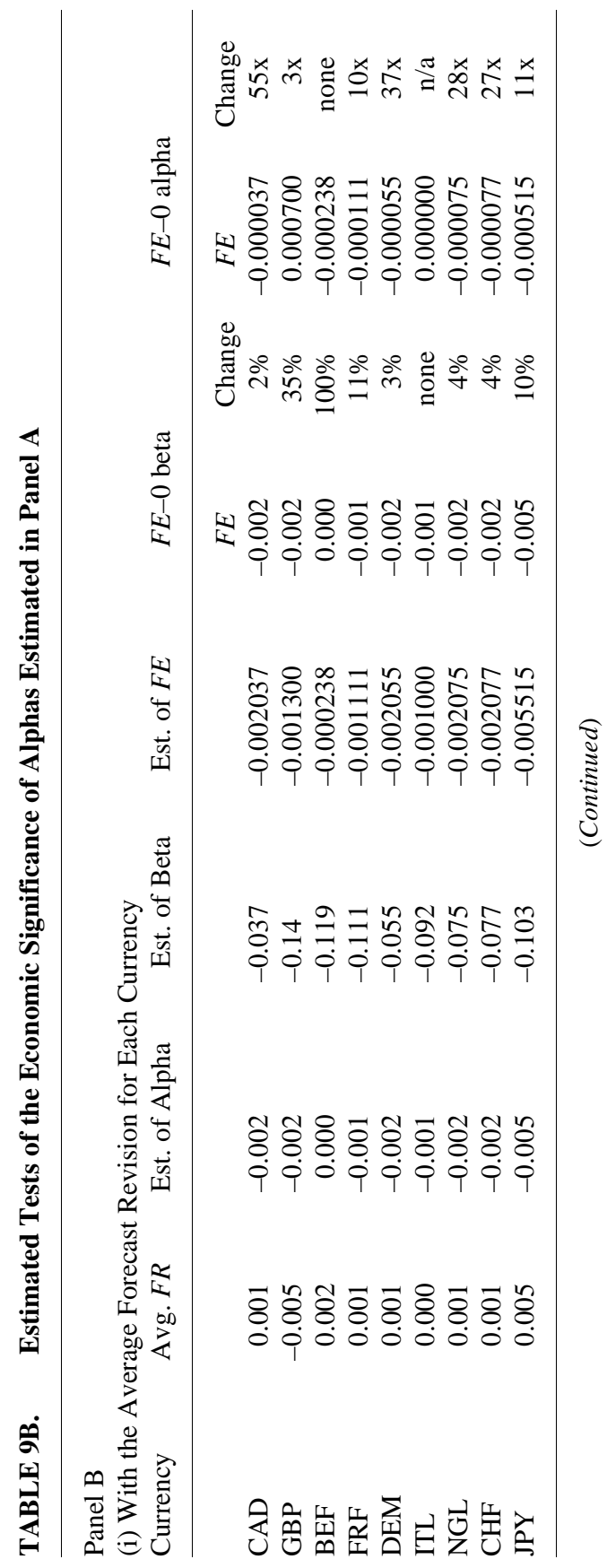




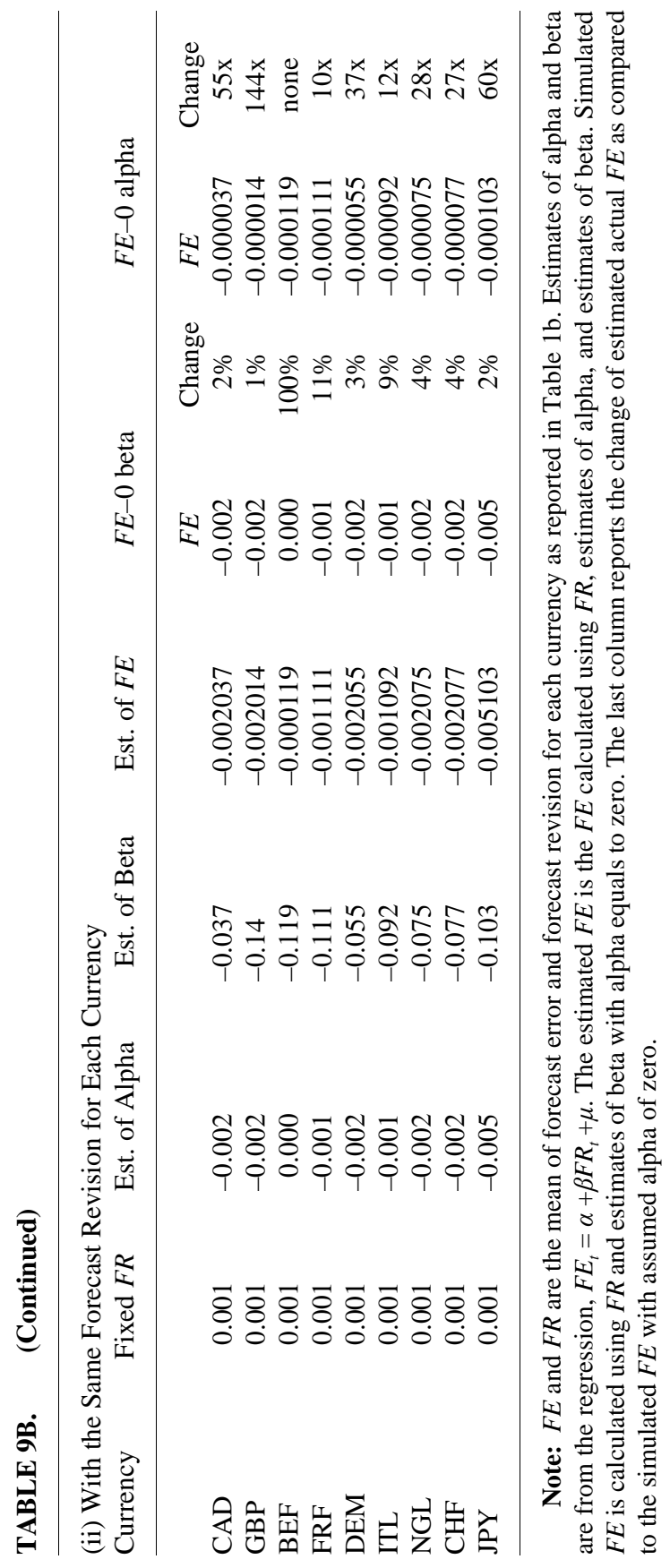


coefficients for the over- reaction groups differ somewhat with six of them being negative (pessimism) and only three (Dutch Guilder, German Mark, and Belgian Franc) being positive (optimism). Overall, these results indicate general under-reaction and pessimism in revisions.

The results presented in table 9 panel A are economically very important. Table 9 panel B reports estimates of the economic significance of the estimated alpha and beta coefficients for each currency. This panel compares estimates of $F E$ based on the equation estimated in panel A with the $F E$ based on assuming an alpha of zero and separately assuming a beta of zero. The top part compares these two estimates of $F E$ using the average $F R$ for that currency while the bottom part of this panel compares the two estimates of $F E$ using a standard $F R$ that is the same for all currencies. The estimates of beta are economically important as using estimated betas make important differences in estimated FEs. However, as the last column indicates, the economic importance of alpha is many times greater. Using the estimated alpha results in an estimated $F E$ that is many multiples of the $F E$ estimated when assuming an alpha of zero. As the variables involved are all small numbers, as are the estimated alphas, clearly the estimated alphas are both statistically significant and economically important.

\section{Conclusions}

The relation between spot and forward rates in the currency markets is important for many economic decisions including investing, hedging, and economic policymaking. However, this relationship remains an empirical and theoretical puzzle and there is much debate about the extent to which the forward rate is an unbiased forecast of the future spot rate.

As in recent literature on over- and under-reaction in other asset (equity) markets and in the revision behavior of economic forecasters and financial analysts, this paper assesses pessimism/optimism and under/over-reaction in revisions of forward rates as forecasts of the future spot rate for the currencies of the nine major industrialized countries. It is documented that for forward rates as forecasts of future spot rates, the rationality hypothesis is firmly rejected and revisions in forward rates as forecasts of future spot rates reflect significant systematic pessimism and systematic under- reaction to new information. These results are robust to alternative research methodologies and hold both for the pooled data set and for the nine currencies examined.

In spite of the extraordinarily high trading volumes in currency 
markets, these results documenting the non-rational behavior of changes in forward exchange rates are consistent with similar behavioral biases observed in other asset markets. The results presented here have important implications for policy-makers, currency overlay managers, and other investors. For example, the results documented here suggest investment strategies for extraordinary returns as investors who account for the behavioral biases reflected in forward rates can expect to achieve higher risk-adjusted returns.

\section{References}

Abel, A. B. 2002. An exploration of the effects of pessimism and doubt on asset returns. Journal of Economic Dynamics and Control 26(7-8): 1075-1092.

Aggarwal, R. 2004. Puzzles in international economics and finance: Central Bank of Ireland Edgeworth Lecture. Economic and Social Review 35(1): 241-250.

Aggarwal, R.; Mohanty, S.; and Song, F. 1995. Are survey forecasts of macroeconomic variables rational? Journal of Business 68 (1): 99-119.

Amir, E., and Ganzach, Y. 1998. Overreaction and under reaction in analyst's forecast. Journal of Economic Behavior and Organization 37(3): 333-347.

Ashiya, M., and Doi, T. 2001. Herd behavior of Japanese economists. Journal of Economic Behavior \& Organization 46(3): 343-346.

Ashiya, M. 2002. Accuracy and rationality of Japanese institutional forecasters. Japan and the World economy 14 (2): 203-213.

Bacchetta, P., and Van Wincoop, E. 2005. Rational inattention: A solution to the forward discount puzzle? NBER Working Paper No. 11633, September.

Backus, D. K.; Gregory, A.; and Velmer, C. I. 1993. Accounting for forward rates in markets for foreign currency. Journal of Finance 48 (6): 1887-1908.

Baillie, R. T. 1988. Econometric tests of rationality and market efficiency. Econometrics and Economic Theory, Michigan State. Papers 8805.

Ball, L., and Croushore, D. 2001. Expectations and the Effects of monetary policy. Federal Reserve Bank of Philadelphia, Working Paper No. 01-12, August.

Bansal, R. A.; Gallant, R.; Hussey, R.; and Tauchen, G. 1995. Non-parametric Estimation of structural models for high frequency currency market data. Journal of Econometrics 66(2): 251-287.

Barberis, N.; Schleifer, A.; and Vishny, R. 1998. A model of investor sentiment. Journal of Financial Economics 49(3): 307-343.

Bekaert, G.; Hodrick, R.; and Marshall, D. 1997. The implications of first order risk aversion for asset market risk premiums. Journal of Monetary Economics 40(1): 3-39.

Bekaert, G., and Hodrick, R. 2001. Expectation hypotheses tests Journal of 
Finance 56(4): 1357-1394.

Bonser-Neal, C. 1996. Does central bank intervention stabilize foreign exchange rates? Federal Reserve Bank of Kansas City Economic Review (No. 1, First Quarter), pp. 43-57.

Cavaglia, S; Verschoor, W. F. C.; and Wolff, C. C. P. 1994. On the biasedness of forward foreign exchange rates: Irrationality or risk premia? Journal of Business 67(3): 321-343.

Cecchetti, S. G.; Lam, P.-S.; and Mark, N. C. 2000. Asset pricing with distorted beliefs: Are equity returns too good to be true? American Economic Review 90(4): 787-805.

Chernenko, S.; Schwarz, K. B.; and Wright, J. H. 2004. The information content of forward and futures prices: Market expectations and the price of risk. FRB International Finance discussion paper no. 808.

Cumby, R. 1988. Is it Risk? Explaining deviations from uncovered interest rate parity Journal of Monetary Economics 22(2): 279-299.

Daniel, K. D.; Hirshleifer, D.; and Subrahmanyam, A. 1998. Investor psychology and security market under- and over-reactions. Journal of Finance 53: 1839-1886.

Daniel, K. D., and Titman, S. 1999. Market efficiency in an irrational world. Financial Analysts Journal 55(6): 28-40.

DeGrauwe, P.; Dieci, R.; and Grimaldi, M. 2005. Fundamental and non-fundamental equilibiria in the foreign exchange market: A behavioral finance framework. CESifo Working Paper No. 1431, March.

DeLong, J. Bradford; Shleifer, A.; Summers, L. H.; and Waldmann, R. J. 1990. Positive feedback investment strategies and destabilizing rational speculation. Journal of Finance 45(2): 887-908.

Easterwood, J., and Nut, S. 1999. Inefficiency in analysts' earnings forecasts: Systematic misreaction or systematic optimism? Journal of Finance 54 (5): 1777-1797.

Engel, C. 1996. The forward discount anomaly and the risk premium: A survey of recent evidence. Journal of Empirical Finance 3(3): 123-192.

Frankel, J. A., and Froot, K. A. 1986. Interpreting tests of forward discount bias using survey data on exchange rate expectations. NBER Working Paper No. 1963.

Frankel, J. A., and Froot, K. A. 1989. Forward discount bias: is it an exchange risk premium? Quarterly Journal of Economics 104(1): 139-161.

Frankel, J. A. and Froot, K. A. 1990. Chartists, Fundamentalists, and trading in the foreign exchange markets. American Economic Review 80(2): 181-185.

Frankel, J. A. and Rose, A. 1994. A Survey of empirical research on nominal exchange rates. National Bureau of Economic Research, Working Paper No. 4865.

Ghosh, S. 1997. United States trade balance announcements: The nature of its data revisions. Oxford Bulletin of Economics and Statistics 59(3): 371-383.

Hansen, L., and Hodrick, R. 1983. Risk averse speculation in the forward 
foreign exchange market in Jeffrey A. Frankel, (Ed.), Exchange Rates and International Macroeconomics. University of Chicago Press, pp. 113-142

Hirshleifer, D. 2001. Investor psychology and asset pricing. Journal of Finance 56(4): 1533-1597.

Hollifield, B., and Uppal, R. 1997. An examination of uncovered interest rate parity in segmented international commodity markets. Journal of Finance 52(5): 2145-2170.

Humpage, O. 1987. Should we intervene in exchange markets? Federal Reserve Bank of Cleveland Economic Commentary (February 1), pp. 1-4.

Jackson, A., and Johnson, T. 2006. Unifying underreaction anomalies. Journal of Business 79(1): 75-114.

Karamanoiu, I., and Raedy, J. S. 2000. Financial analysts' forecasting revisions as evidence of the usefulness of form $20 \mathrm{f}$ reconciliation and disclosures. SSRN Working Paper.

Lakonishok, J.; Shleifer, A.; and Vishny, R. 1994. Contrarian investment, extrapolation, and risk. Journal of Finance 49(5):1541-1578.

La Porta, R. 1996. Expectations and the cross-section of stock returns. Journal of Finance 49(5): 1715-1742.

Levich, R. M. 1979 On the efficiency of markets fore foreign exchange in Dornbusch, R., Frankel, J. (Eds.), International Economic Policy Theory and Evidence. John Hopkins Press, pp. 246-267.

Lewis, K. K. 1989. Changing beliefs and systematic rational forecast errors with evidence from foreign exchange. American Economic Review 79(4): 621-636.

Lewis, K. K. 1995. Puzzles in international financial markets in G. Grossman and Kenneth Rogoff (Eds.), Handbook of International Economics. Elsevier Science, pp. 1913-1971.

MacDonald, R., and Taylor, M. F. 1992. Exchange rate economics: A survey. IMF Staff Papers 39(1): 1-57.

Nofsinger, J. R., and Sias, R.W. 1999. Herding and feedback trading by institutional and individual investors. Journal of Finance 54(6): 2263-2295.

Poteshman, A. M. 2001. Underreaction, overreaction, and increasing misreaction to information in the options market. Journal of Finance 56(3): 851-876.

Shiller, R. J. 2002. Bubbles, human judgment, and expert opinion. Financial Analysts Journal 58(3): 18-26.

Shleifer, A., and Vishny, R. W. 1997. The limits of arbitrage. Journal of Finance 52(1): 35-55.

Villanueva, O. M. 2005. FX Dynamics, limited participation, and the forward bias anomaly. Financial Review 40(1): 67-93.

Wermers, R. 1999. Mutual fund herding and the impact on stock prices. Journal of Finance 54(2): 581-622.

Zivot, E. 2000. Cointegration and forward and spot exchange rate regressions. Journal of International Money and Finance 19(6): 785-812. 